\title{
A brief review of graphene-based material synthesis and its application in environmental pollution management
}

\author{
LÜ Kui ${ }^{1,2}$, ZHAO GuiXia ${ }^{2} \&$ WANG XiangKe ${ }^{2 *}$ \\ ${ }^{1}$ Key Laboratory of Audit Information Engineering, Nanjing Audit University, Nanjing 210029, China; \\ ${ }^{2}$ Key Laboratory of Novel Thin Film Solar Cells, Institute of Plasma Physics, Chinese Academy of Sciences, Hefei 230031, China
}

Received November 15, 2011; accepted December 27, 2011; published online February 21, 2012

\begin{abstract}
Graphene is an interesting two-dimensional carbon allotrope that has attracted considerable research interest because of its unique structure and physicochemical properties. Studies have been conducted on graphene-based nanomaterials including modified graphene, graphene/semiconductor hybrids, graphene/metal nanoparticle composites, and graphene-complex oxide composites. These nanomaterials inherit the unique properties of graphene, and the addition of functional groups or the nanoparticle composites on their surfaces improves their performance. Applications of these materials in pollutant removal and environmental remediation have been explored. From the viewpoint of environmental chemistry and materials, this paper reviews recent important advances in synthesis of graphene-related materials and their application in treatment of environmental pollution. The roles of graphene-based materials in pollutant removal and potential research are discussed.
\end{abstract}

graphene, graphene-based material, environmental remediation, pollution

Citation: Lü K, Zhao G X, Wang X K. A brief review of graphene-based material synthesis and its application in environmental pollution management. Chin Sci Bull, 2012, 57: 1223-1234, doi: 10.1007/s11434-012-4986-5

Since the discovery of fullerene and carbon nanotubes (CNTs), research has focused on another allotrope of carbon, graphene. Graphene is a two-dimensional nanomaterial that has between one and ten layers of $s p^{2}$-hybridized carbon atoms arranged in six-membered rings. It has many unique properties, including interesting transport phenomena, and high Young's modulus (approximately $1100 \mathrm{GPa}$ ) [1], fracture strength $(125 \mathrm{GPa})[1]$, thermal conductivity (approximately $5000 \mathrm{~W} \mathrm{~m}^{-1} \mathrm{~K}^{-1}$ ) [2], mobility of charge carriers $\left(200000 \mathrm{~cm}^{2} \mathrm{~V}^{-1} \mathrm{~s}^{-1}\right)$ [3], specific surface area (theoretical value of $2630 \mathrm{~m}^{2} \mathrm{~g}^{-1}$ ) [4], and chemical stability. Its synthesis has been investigated in many different fields with potential applications in biomedicines, reinforced composites, sensors, catalysis, energy conversion, and storage devices. Importantly, it could be used in pollutant removal in environmental remediation, which has attracted increasing research in recent few years [5-10] and is the focus of this

*Corresponding author (email: xkwang@ipp.ac.cn) review.

Aggregation of graphene layers determines the practical specific surface area, and modification of pristine graphene with other compounds will decrease the aggregation and increase the effective surface area. Graphene with a high specific surface area has a large enough area for pollutant removal and functionalization. Modification of the graphene surface with specific functional groups or nanoparticles could be used to increase the graphene interaction with organic and inorganic pollutants, so they can be removed efficiently from solution through catalytic adsorption or degradation. Based on this, various graphene-based materials have been synthesized; these have enhanced new properties compared to pristine graphene.

In this paper, we review recent research advances in graphene-based nanomaterial synthesis and the application of these materials to environmental remediation. Potential future research on high-performance graphene-based nanomaterials for pollutant removal is discussed. 


\section{Synthesis of graphene-based materials for pollutant removal}

\subsection{Pristine graphene}

Graphene can be synthesized by different methods, which include micromechanical cleavage $[11,12]$, chemical vapor deposition [13-18], epitaxial growth on silicon carbide [19-22], arc discharge [23,24], unzipping of carbon nanotubes [25-27], electrochemical synthesis [28-30], total organic synthesis [31-37], chemical reduction of graphene oxides [38,39], and plasma discharge etching of graphite. For application in environmental pollution management, the graphene synthesis should be inexpensive, efficient on a large-scale, and simple. Therefore, not all these methods are practical for environmental application. To date, only a few studies have investigated the synthesis of pristine graphene for environmental remediation applications. Li et al. [40] used a facial liquid phase exfoliation of worm-like graphite to obtain either a monolayer or a few layers of graphene sheets by ultrasonication and centrifugation of a 1-methyl2-pyrrolidinone (NMP) suspension. After removal of NMP at $200^{\circ} \mathrm{C}$, the graphene was used to adsorb fluoride from aqueous solutions. Comparison with other adsorbents the prepared graphene had an excellent adsorption capacity of up to $35 \mathrm{mg} / \mathrm{g}$ at $298 \mathrm{~K}$. In a similar manner, Ramesha et al. [41] obtained reduced graphene oxide (RGO) by reducing the exfoliated graphene oxide. The RGO, which had a high surface area and lacked a high negative surface charge, was a good adsorbent for anionic dyes.

\subsection{Modified graphene}

Pristine graphene is so hydrophobic that it is difficult to disperse in water for the pollutant removal. To improve its solubility, modified graphenes have been synthesized by adding functional groups on the surface through chemical modification, covalent, or noncovalent functionalization.
Graphene oxide, which is produced by Hummers method from flake graphite, has disrupted conjugation in the graphene plane and abundant functional groups, such as epoxide, hydroxyl, carboxyl and carbonyl, on its surfaces. These oxygen-containing groups could form strong complexes with metal ions, and allow the graphene oxide to act as an adsorbent for heavy metal ion preconcentration and removal. According to Zhao's group [42], graphene oxide with a few layers had a higher adsorption capacity for $\mathrm{Pb}$ (II) ions (up to $842 \mathrm{mg} / \mathrm{g}$ ) than reduced graphene oxide (400 mg/g) (Figure 1). This type of graphene oxide was also used to remove methylene blue from aqueous solution [43], and the adsorption capacity was $714 \mathrm{mg} / \mathrm{g}$.

In 2010, Deng et al. [44] reported a one-step synthesis of ionic-liquid-functionalized graphene sheets directly from flake graphite. The ionic-liquid-treated graphite sheets were exfoliated into functionalized graphene nanosheets with a $\mathrm{PF}_{6}^{-}$mass fraction of $30 \%$. These nanosheets were used for removal of $\mathrm{Pb}(\mathrm{II})$ and $\mathrm{Cd}(\mathrm{II})$ ions from wastewater with adsorption capacities of 406 and $73 \mathrm{mg} / \mathrm{g}$, respectively.

Recently, sulfonated graphene with a few layers was synthesized in several steps by Zhao et al. [45]. The prepared sulfonated graphene had a high specific surface area $\left(529 \mathrm{~m}^{2} / \mathrm{g}\right)$ and high dispersion in aqueous solutions. Benzenesulfonic groups on the graphene surfaces were thought to contribute to these properties (Figure 2).

The prepared sulfonated graphene was applied as an adsorbent to remove naphthalene and 1-naphthol from aqueous solutions. The adsorption isotherms (Figure 3) of naphthalene and 1-naphthol on these sulfonated graphene nanosheets indicated the maximum adsorption capacities were 2.33 $\mathrm{mmol} / \mathrm{g}$ for naphthalene and $2.41 \mathrm{mmol} / \mathrm{g}$ for 1 -naphthol, which was the highest adsorption capacities observed to date.

The adsorption of naphthalene and 1-naphthol on sulfonated graphene sheets can be theoretically modeled. The morphologies (top view and side view) of naphthalene and 1-naphthol adsorbed on the hexagonal carbon network are
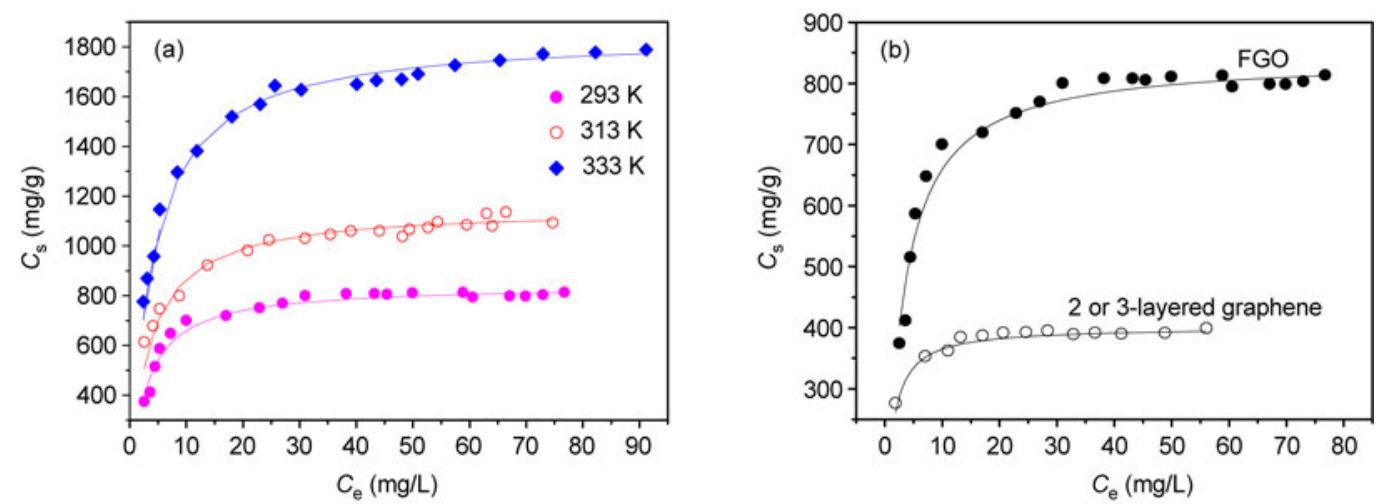

Figure 1 (Color online) (a) Adsorption isotherms of $\mathrm{Pb}(\mathrm{II})$ on few-layered graphene oxide (FGO) at three different temperatures. $\mathrm{pH} 6.0 \pm 0.1$, [NaClO 4$]=$ $0.01 \mathrm{~mol} / \mathrm{L}, m / V=0.1 \mathrm{~g} / \mathrm{L}$. (b) Adsorption isotherms of $\mathrm{Pb}(\mathrm{II})$ on FGO and on 2- or 3-layered graphene at $T=293 \mathrm{~K}$. The solid symbols are for FGO, and the open symbols for 2- or 3-layered graphene. $\mathrm{pH} 6.0 \pm 0.1, \mathrm{C}\left[\mathrm{NaClO}_{4}\right]=0.01 \mathrm{~mol} / \mathrm{L}, \mathrm{m} / \mathrm{V}=0.1 \mathrm{~g} / \mathrm{L}$. Reprinted with permission from [42], Copyright 2011, Royal Society of Chemistry. 


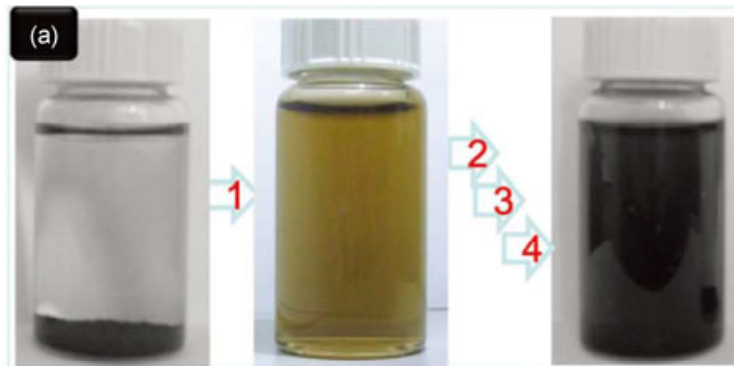

1, Modified Hummers method; 2, preproduction with $\mathrm{NaBH}_{4}$; 3 , diazotization reaction; 4 , postreduction with hydrazine hydrate

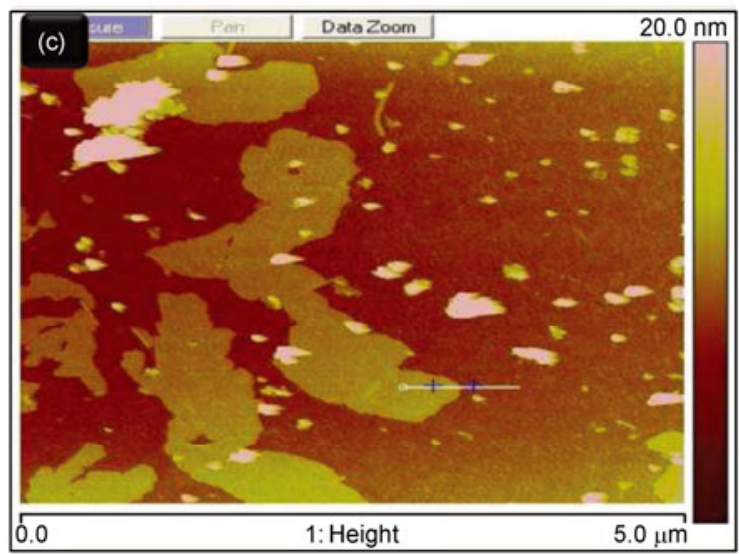

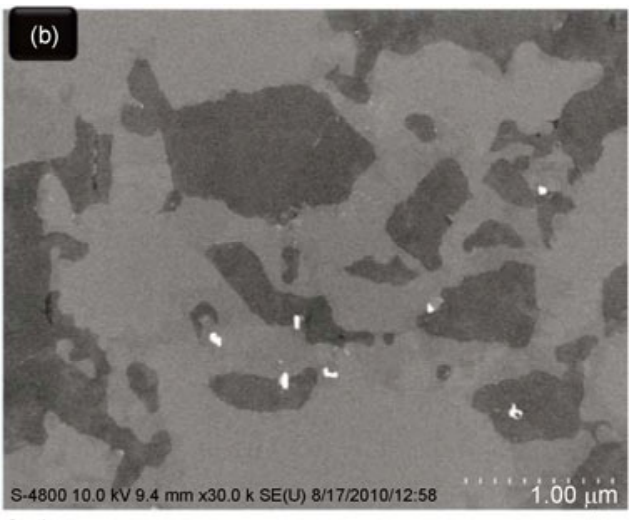

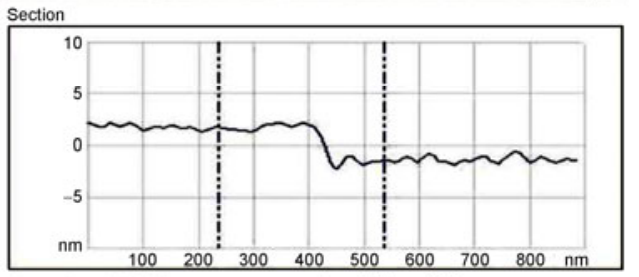

Spectral period $0.920 \mu \mathrm{m} \quad$ Spectral freq $1.09 \mu \mathrm{m}$ Spectral RMS ampl. $1.34 \mathrm{~nm} \quad$ Temporal freq $0.00 \mathrm{~Hz}$

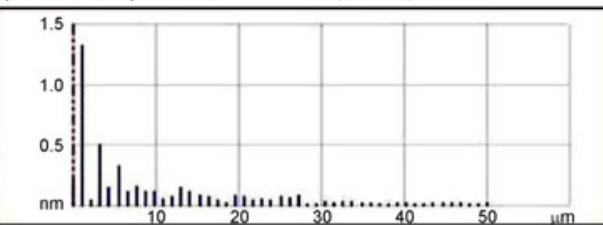

Figure 2 (a) Synthesis of sulfonated graphene from graphite. (b) SEM image of sulfonated graphene on Si substrates. (c) AFM image of sulfonated graphene on $\mathrm{Si} / \mathrm{SiO}_{2}$ substrates $\left(\mathrm{SiO}_{2}\right.$ approximately $\left.300 \mathrm{~nm}\right)$. The SEM and AFM images show that sulfonated graphene sheets with a few layers are formed. Reprinted with permission from [45], Copyright 2011, WILEY-VCH Verlag GmbH \& Co. KGaA, Weinheim.
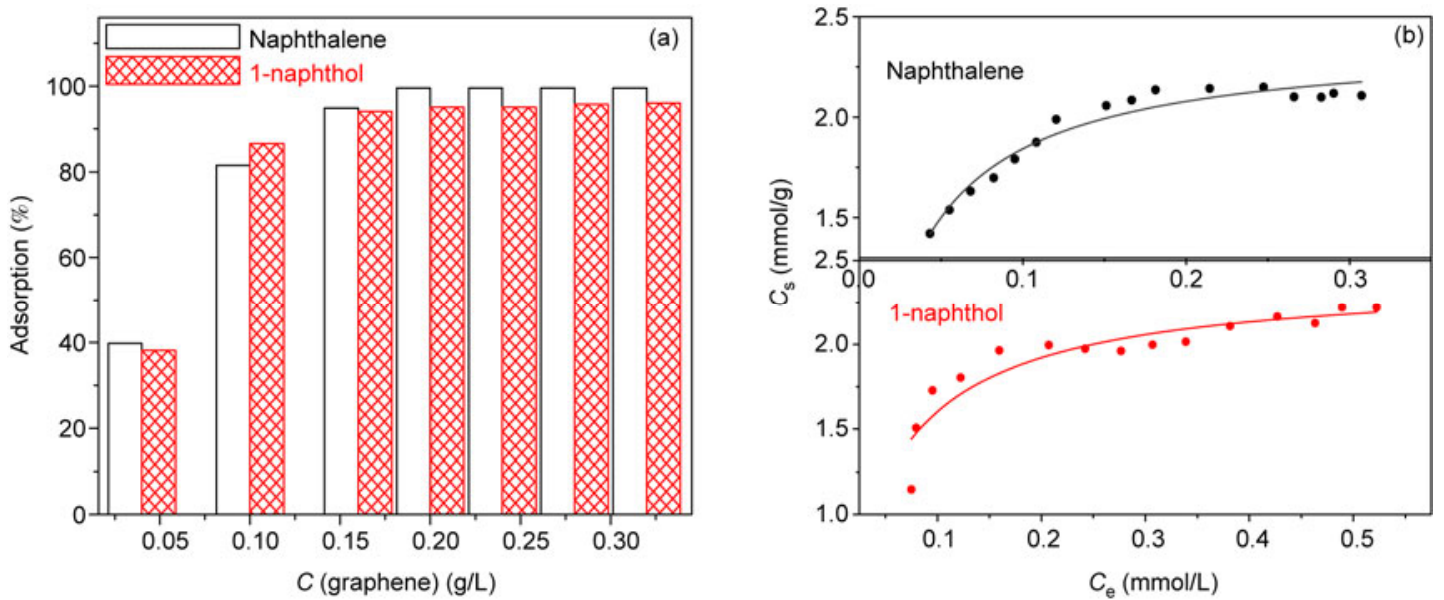

Figure 3 (Color online) (a) Effect of the sulfonated graphene content on the adsorption of naphthalene and 1-naphthol on sulfonated graphene. $C$ (naphthalene/ 1-naphthol) $)_{\text {initial }}=0.2 \mathrm{mmol} \mathrm{L}{ }^{-1}, \mathrm{pH} 7.0 \pm 0.1, I=0.01 \mathrm{~mol} \mathrm{~L}^{-1} \mathrm{NaClO}_{4}, T=293 \mathrm{~K}$. (b) Adsorption isotherms of naphthalene and 1-naphthol on sulfonated graphene. $m / V$ (for naphthalene) $=0.04 \mathrm{~g} \mathrm{~L}^{-1}, m / V$ (for 1-naphthol) $=0.08 \mathrm{~g} \mathrm{~L}^{-1}, \mathrm{pH} 7.0 \pm 0.1, I=0.01 \mathrm{~mol} \mathrm{~L}^{-1} \mathrm{NaClO}_{4}, T=293 \mathrm{~K}, C$ (naphthalene) ${ }_{\text {initial }}=0.10$ $-0.39 \mathrm{mmol} \mathrm{L}^{-1}, C$ (1-naphthol) $)_{\text {initial }}=0.17-0.70 \mathrm{mmol} \mathrm{L}^{-1}$. Reprinted with permission from [45], Copyright 2011, WILEY-VCH Verlag GmbH \& Co. KGaA, Weinheim.

shown in Figure 4. The naphthalene molecule adsorbed parallel to the sulfonated graphene surface in one of two possible orientations, while 1-naphthol adsorbed perpendicular to the sulfonated graphene surface in one orientation. In the two naphthalene adsorption orientations, the naphthalene was either $3.57 \AA$ (State I) above the sulfonated graphene surface with a release energy of $1.96 \mathrm{kcal} / \mathrm{mol}$ or $3.71 \AA$ (State II) above the sulfonated graphene surface with a release 

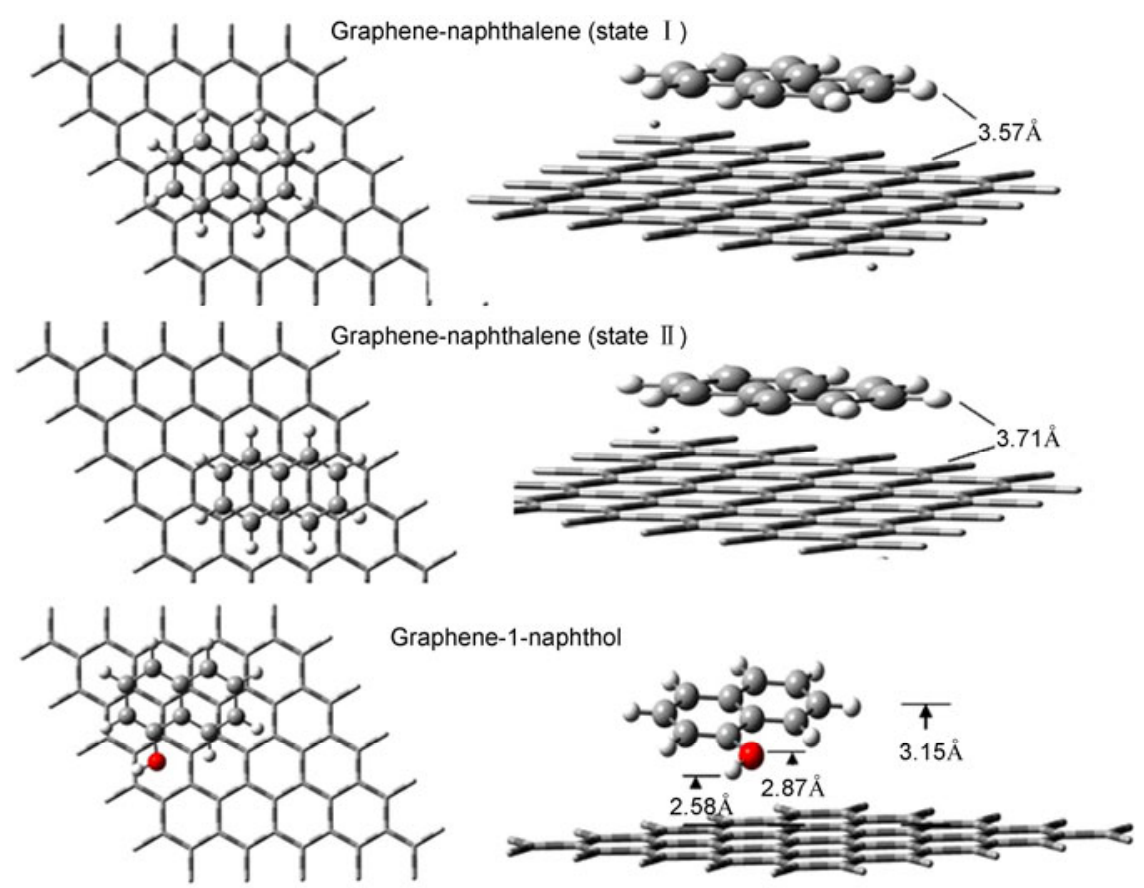

Figure 4 (Color online) Top view and side view of naphthalene and 1-naphthol on the hexagonal carbon network according to the calculation. Reprinted with permission from [45], Copyright 2011, WILEY-VCH Verlag GmbH \& Co. KGaA, Weinheim.

energy of $2.01 \mathrm{kcal} / \mathrm{mol}[45]$.

\subsection{Graphene/semiconductor hybrids}

There is great interest in the synthesis of graphene-semiconductor composites because of the diversity of available functional semiconductor particles, which include $\mathrm{Fe}_{3} \mathrm{O}_{4}$, $\mathrm{TiO}_{2}, \mathrm{ZnO}, \mathrm{CdS}$. In pollutant removal, these semiconductors often modify the properties of the graphene framework. For example, magnetic $\mathrm{Fe}_{3} \mathrm{O}_{4}$ nanoparticles can be used for magnetic separation, which is useful in large-scale industrial applications and overcomes many issues associated with filtration, centrifugation, or gravitational separation of graphene. Other semiconductors, such as $\mathrm{ZnO}, \mathrm{TiO}_{2}$, and $\mathrm{CdS}$, are common photocatalysts. Because graphene is a zeroband gap semiconductor and has excellent electronic conductivity in storage and transport of electrons, when combined with these semiconductor catalysts it should be very active in photocatalytic applications. In these graphene/ semiconductor hybrids, the nanoparticles on the graphene surface prevent aggregation of the graphene layers to some extent, which increases the surface area for removal of pollutants from aqueous solutions.

Among the composites, graphene-iron oxide hybrids have attracted the most research interest. Shen et al. [46] reported a one-step synthesis for graphene oxide-magnetic nanoparticle composites through a high temperature reaction of ferric triacetylacetonate with graphene oxide in 1-methyl-2pyrrolidone. The iron oxide nanoparticles were $\mathrm{Fe}_{3} \mathrm{O}_{4}$ with a small amount of $\gamma-\mathrm{Fe}_{2} \mathrm{O}_{3}$, and about $8 \mathrm{~nm}$ in diameter. These nanoparticles bound strongly to the graphene surface through metal carbonyl coordination. Another one-pot solvothermal synthesis of graphene-based magnetic nanocomposites was introduced by Shen et al. [47]. Graphene oxide and iron acetylacetonate were dispersed in ethylene glycol, followed by addition of hydrazine hydrate and reaction in an autoclave at $180^{\circ} \mathrm{C}$. In the prepared graphene $/ \mathrm{Fe}_{3} \mathrm{O}_{4}$ nanocomposites, the $\mathrm{Fe}_{3} \mathrm{O}_{4}$ nanoparticles $(\phi 60 \mathrm{~nm})$ were well distributed on the graphene nanosheets. They had no obvious magnetic hysteresis loop at $300 \mathrm{~K}$, which indicates they are superparamagnetic. In a different synthesis, Wang et al. [48] prepared magnetic graphene nanocomposites by in situ chemical coprecipitation of $\mathrm{Fe}^{2+}$ and $\mathrm{Fe}^{3+}$ in alkaline solution in the presence of graphene. The graphene/ $/ \mathrm{Fe}_{3} \mathrm{O}_{4}$ composites with a large surface area of up to several square micrometers were formed from $\mathrm{Fe}_{3} \mathrm{O}_{4}$ nanoparticles (average $\phi$ $20 \mathrm{~nm}$ ) and nearly flat graphene sheets. The authors applied these graphene $/ \mathrm{Fe}_{3} \mathrm{O}_{4}$ composites to the removal of organic dyes from aqueous solutions, and the maximum adsorption capacity for fuchsine $89 \mathrm{mg} / \mathrm{g}$. He's group [49] developed a complicated method to attach $\mathrm{Fe}_{3} \mathrm{O}_{4}$ nanoparticles to graphene oxide by covalent bonding. First, $\mathrm{Fe}_{3} \mathrm{O}_{4}$ nanoparticles were modified with tetraethyl orthosilicate and (3-aminopropyl) triethoxysilane, which introduced amino groups on the surface. Then the modified $\mathrm{Fe}_{3} \mathrm{O}_{4}$ nanoparticles were reacted with the carboxylic groups of graphene oxide in the presence of 1-ethyl-3-(3-dimethyaminopropyl) carbodiimide and $N$-hydroxysuccinnimide to form the graphene oxide$\mathrm{Fe}_{3} \mathrm{O}_{4}$ hybrids. The adsorption capacities of these hybrids for methylene blue and neutral red cationic dyes were 190 
and $140 \mathrm{mg} / \mathrm{g}$, respectively. For the removal of arsenic, Chandra et al. [50] synthesized magnetic-graphene hybrids through chemical coprecipitation of $\mathrm{Fe}^{2+}$ and $\mathrm{Fe}^{3+}$ in the presence of graphene oxide, followed by reduction of graphene oxide using hydrazine hydrate. For adsorption of $\mathrm{As}(\mathrm{III})$ and $\mathrm{As}(\mathrm{V})$ these hybrids showed near complete arsenic removal to as low as $1 \mu \mathrm{g} / \mathrm{L}$ (Figure 5). Because of their high adsorption capacity, and the fact they could be simply separated from solution by application of an external magnetic field, these hybrids could be applied to arsenic removal from large volumes of wastewater.

In addition to adsorption of pollutants from water, many pollutants can be eliminated by photocatalytic degradation. When traditional photocatalysts, such as $\mathrm{ZnO}, \mathrm{TiO}_{2}$, and $\mathrm{CdS}$, are incorporated with graphene, the hybrid should display high catalytic activity for degradation of organic pollutants because of graphene is a zero-band gap semiconductor. Liang et al. [51] synthesized graphene/ $\mathrm{TiO}_{2}$ nanocrystal hybrids by directly growing $\mathrm{TiO}_{2}$ nanocrystals on graphene oxide nanosheets. First $\mathrm{TiO}_{2}$ was coated on graphene oxide sheets by hydrolysis, and then the $\mathrm{TiO}_{2}$ parti- cles were crystallized into anatase nanocrystals by hydrothermal treatment (Figure 6). With ethanol/water as a mixed solvent and $\mathrm{H}_{2} \mathrm{SO}_{4}$ as an additive, the hydrolysis was slow, growth of $\mathrm{TiO}_{2}$ on the graphene oxide was selective, and growth of free $\mathrm{TiO}_{2}$ in solution was suppressed. This method provides an easy approach to synthesize graphene/ $/ \mathrm{TiO}_{2}$ nanocrystal hybrids with a uniform coating and strong interactions between the $\mathrm{TiO}_{2}$ and the underlying graphene nanosheets. The graphene/ $\mathrm{TiO}_{2}$ nanocrystal hybrids showed superior photocatalytic activity to other $\mathrm{TiO}_{2}$ materials, with an impressive three-fold photocatalytic enhancement over P25 particles.

Using a one-step hydrothermal reaction, Zhang et al. [52] demonstrated a facile and reproducible route to obtain chemically bonded $\mathrm{TiO}_{2}(\mathrm{P} 25)$-graphene composites. In their synthesis, P25 and graphene oxide were mixed in a homogeneous suspension, which was reacted in an autoclave to reduce graphene oxide and deposit P25 on the carbon substrate. The composites showed high pollutant adsorption capacities, extended light absorption ranges, and facile charge transportation and separation. These attributes meant (a)

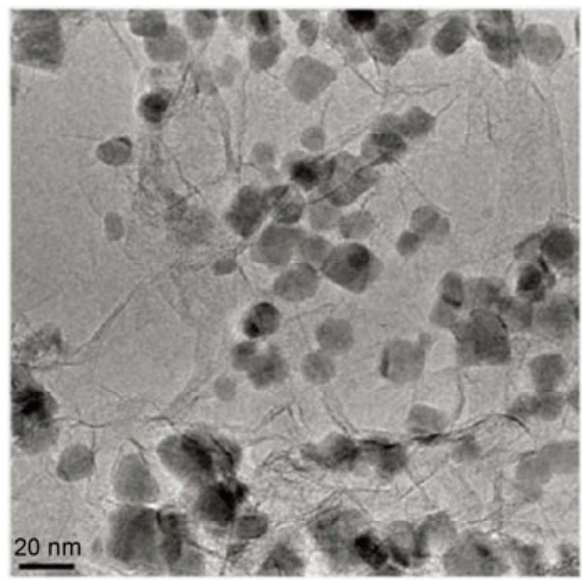

(b)

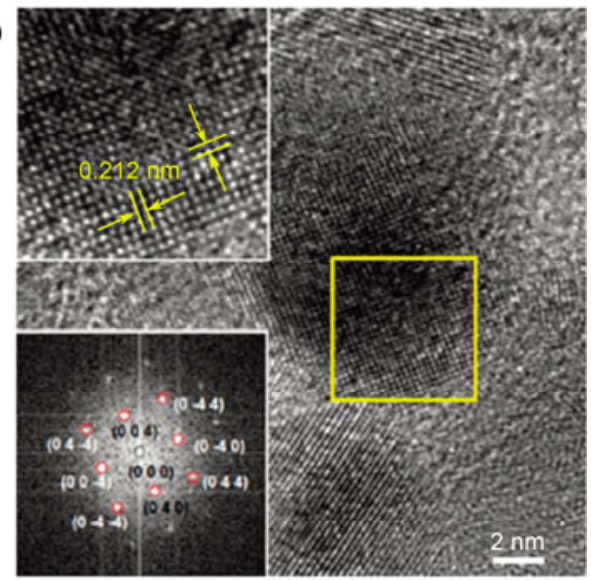

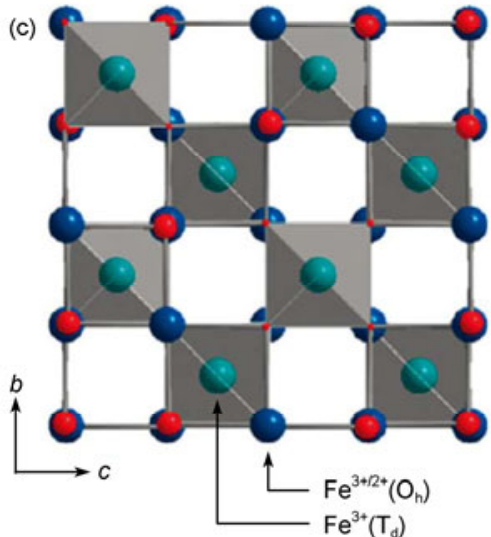

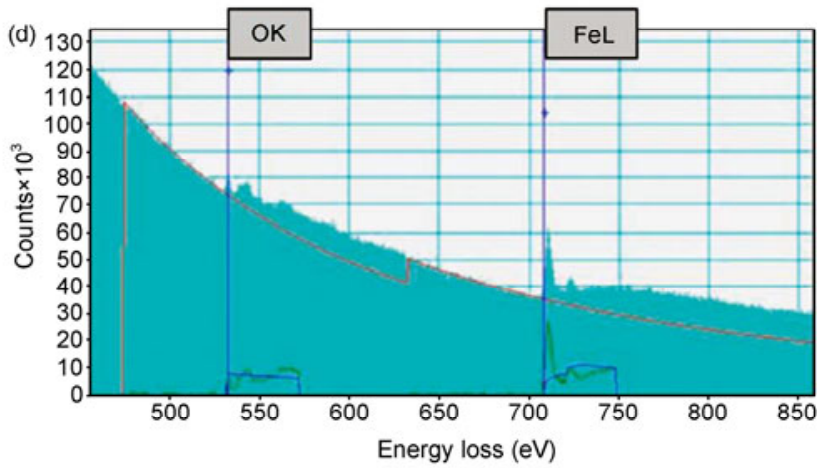

Atomic percent ratio; $\mathrm{Fe}(43.75 \%): \mathrm{O}(56.25 \%)$

Figure 5 (Color online) TEM analysis of $\mathrm{Fe}_{3} \mathrm{O}_{4}$ nanoparticles. (a) TEM image of M-RGO. (b) HRTEM image and selected area diffraction pattern of M-RGO. The top inset shows a magnified image of the lattice fringes with an interlayer distance of $0.212 \mathrm{~nm}$ corresponding to the (400) plane. (c) Unit cell structure of $\mathrm{Fe}_{3} \mathrm{O}_{4}$-inverse spinel type where $\mathrm{O}_{\mathrm{h}}$ and $\mathrm{T}_{\mathrm{d}}$ correspond to octahedral $\left(\mathrm{Fe}^{3+} /^{2+}\right)$ and tetrahedral $\left(\mathrm{Fe}^{3+}\right)$ polyhedron, respectively. $(\mathrm{d})$ EELS spectrum of $\mathrm{Fe}_{3} \mathrm{O}_{4}$ nanoparticles in $\mathrm{M}-\mathrm{RGO}$ with atomic ratios of $\mathrm{Fe}(43.75 \%)$ and $\mathrm{O}(56.25 \%)$, indicating the $\mathrm{OK}$ shell ionization edge and the FeL $\mathrm{L}_{2}$ and $\mathrm{FeL}_{3}$ shell ionization edges. Reprinted with permission from [50], Copyright 2010, American Chemical Society. 

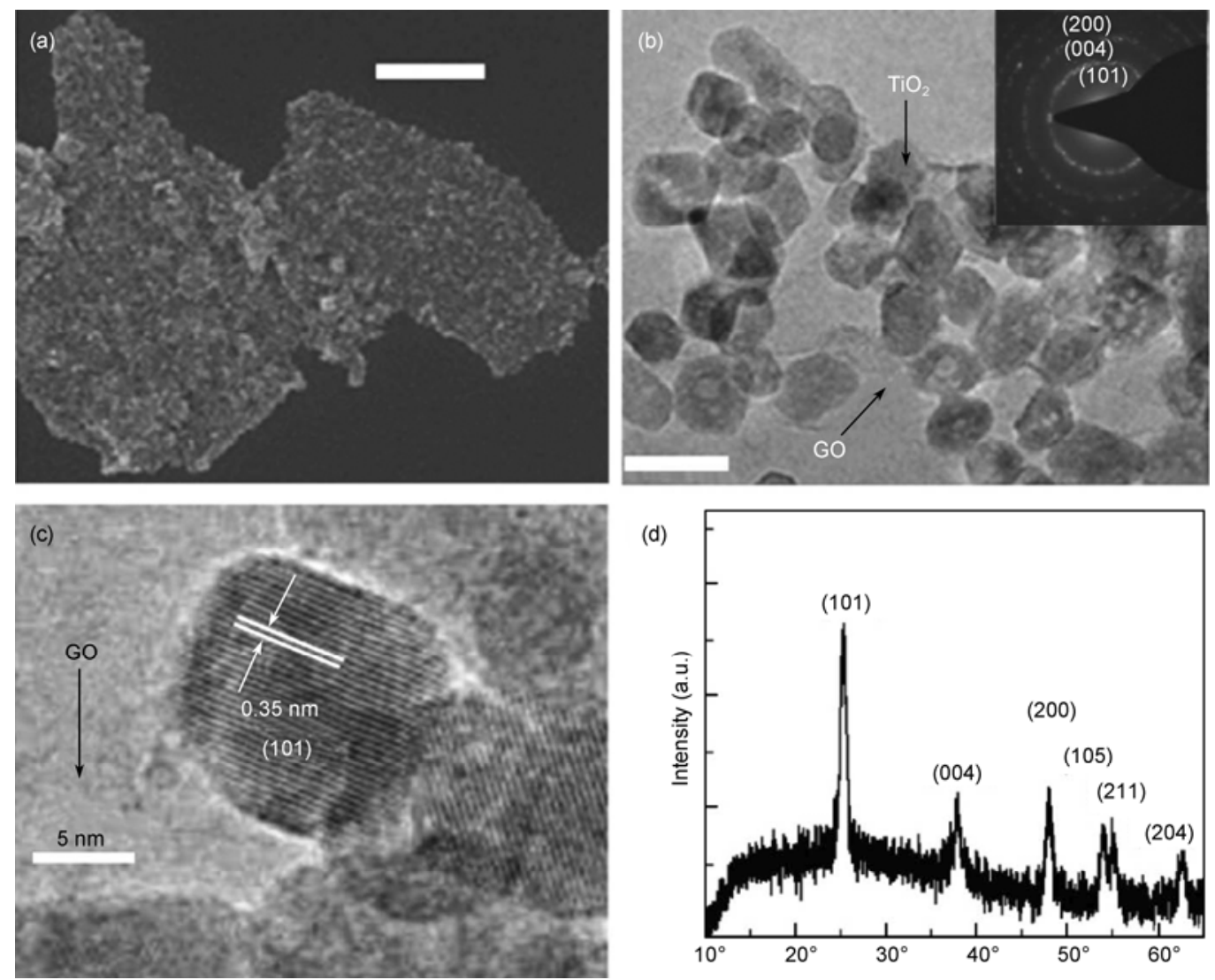

Figure 6 (a) SEM image; (b) low magnification; (c) high magnification TEM images of $\mathrm{TiO}_{2}$ nanocrystals grown on GO sheets; (d) an XRD pattern of the graphene $/ \mathrm{TiO}_{2}$ nanocrystals hybrid. The scale bar is $400 \mathrm{~nm}$ for the SEM image in (a) and $20 \mathrm{~nm}$ for the TEM image in (b). Reprinted with permission from [51], Copyright 2010, Springer Science + Business Media.

the composites could be applied to the environmental remediation.

Zhang et al. [53] investigated the synthesis of $\mathrm{ZnO}$ /graphene composites via a chemical deposition route and its influence on photocatalytic degradation. In the synthesis process, $\mathrm{Zn}$ (II) was adsorbed on the surface of graphene oxide by complete ion exchange, then $\mathrm{NaOH}$ was added, and the solid was dried at $150^{\circ} \mathrm{C}$. The resulted powder was redispersed in a solution of $\mathrm{NaBH}_{4}$ for further hydrothermal treatment at $120^{\circ} \mathrm{C}$. The prepared composites exhibited efficient photosensitized electron injection, slow electron recombination, and enhanced photocatalytic activity under UV and visible light conditions.

$\mathrm{CdS}$ is a well-known II-VI semiconductor that has received extensive attention in photocatalytic research because it a band gap $(2.4 \mathrm{eV})$ that corresponds well with the spectrum of sunlight. Many syntheses for CdS-graphene composites have been reported. For instance, Nethravathi et al. [54] and Wang et al. [55] bubbled $\mathrm{H}_{2} \mathrm{~S}$ gas into a solution containing $\mathrm{Cd}\left(\mathrm{NO}_{3}\right)_{2}$ and graphene oxide. Chang et al. [56] prepared the composites by in situ growth of $\mathrm{CdS}$ on pyrenebutyrate functionalized graphene. Although none of these composites were applied as photocatalyst in pollutant removal and degradation, the reported syntheses are im- portant for CdS-graphene hybrids. By microwave-assisted synthesis, Liu et al. [57] synthesized CdS-reduced graphene oxide composites for photocatalytic reduction of $\mathrm{Cr}(\mathrm{VI})$. This one-step synthesis was carried out by mixing the $\mathrm{Cd}(\mathrm{II})$ solution, a $\mathrm{CH}_{4} \mathrm{~N}_{2} \mathrm{~S}$ solution, and a graphene oxide suspension ( $\mathrm{pH}$ 9), and irradiating the mixture with a microwave at $150^{\circ} \mathrm{C}$. The CdS-graphene composites were better photocatalysts than pure $\mathrm{CdS}$, the performance was dependent on the proportion of graphene in the composite, and the composites containing $1.5 \%$ (mass fraction) graphene gave the highest $\mathrm{Cr}(\mathrm{VI})$ removal rate $(92 \%)$.

\subsection{Graphene/metal nanoparticle hybrids}

Noble metal nanoparticles, such as those of $\mathrm{Au}$ and $\mathrm{Pt}$, have attracted interest because of their excellent catalysis. Use of graphene sheets as a low-dimensional support for metal nanoparticle growth will enhance the electronic properties of the graphene because of spatial confinement and synergistic interactions between the metal and graphene. According to recent progress in synthetic technologies, metal nanocrystal growth on graphene can be realized by direct chemical reduction of the metal precursors in the presence of graphene oxide or reduced graphene oxide suspensions. 
Muszynski et al. [58] prepared a graphene-Au composite by reduction of $\mathrm{AuCl}_{4}^{-}$with $\mathrm{NaBH}_{4}$ in an octadecylaminefunctionalized graphene suspension. While Scheuermann et al. [59] prepared Pd nanoparticles supported on graphene oxide by bubbling hydrogen through a suspension of $\mathrm{Pd}^{2+}$-graphene oxide in ethanol. The resulting Pd-graphene composites were very active catalysts in the Suzuki-Miyaura coupling reaction (Figure 7).

Goncalves et al. [60] demonstrated that nucleation and growth of gold nanoparticles were dependent on the number of oxygen functional groups on the graphene surface. For better control over the metal nanoparticle size and structure, Zhang et al. [61] developed a facile and green method for in situ growth of noble metal nanodots on graphene sheets through a sonolytic and hydrothermal reduction route using graphene oxide and metal salts as the precursors in aqueous solution. The metal nanodots $(\phi 2 \mathrm{~nm})$ were uniformly distributed on the graphene surface. Because of the special catalytic properties of noble metals, most of these metalgraphene composites have been applied in energy conversion and organic transformations [62-65], rather than in the environmental remediation.
To simplify the post-synthesis treatment and increase the viability of the products for commercial application in pollutant removal, Sreeprasad et al. [66] introduced an in situ homogeneous reduction strategy. This used the inherent reducing properties of reduced graphene oxide to synthesize monodispersed and uncapped nanoparticles of silver, gold, platinum and palladium on the graphene surface. In their synthesis, graphene-metal composites were obtained by incubating a mixture of the metal ion precursors $\left(\mathrm{HAuCl}_{4}\right.$, $\mathrm{AgNO}_{3}, \mathrm{H}_{2} \mathrm{PtCl}_{6}, \mathrm{PdCl}_{2}$ ) and reduced graphene oxide (Figure 8). With sand as a support, graphene-Ag composites showed excellent uptake capacity for $\mathrm{Hg}$ (II) from aqueous solutions. More research concerning the application of graphene-metal composites in pollutant removal is expected.

\subsection{Graphene-complex oxide composites}

In addition to the graphene-metal oxide, graphene-metal, and graphene-sulfide composites, graphene hybrids with complex oxides, such as $\mathrm{CoFe}_{2} \mathrm{O}_{4}$ and $\mathrm{ZnFe}_{2} \mathrm{O}_{4}$, have also been studied. Because of the prominent magnetic properties of $\mathrm{CoFe}_{2} \mathrm{O}_{4}$, Li et al. [67] prepared $\mathrm{CoFe}_{2} \mathrm{O}_{4}$-functionalized
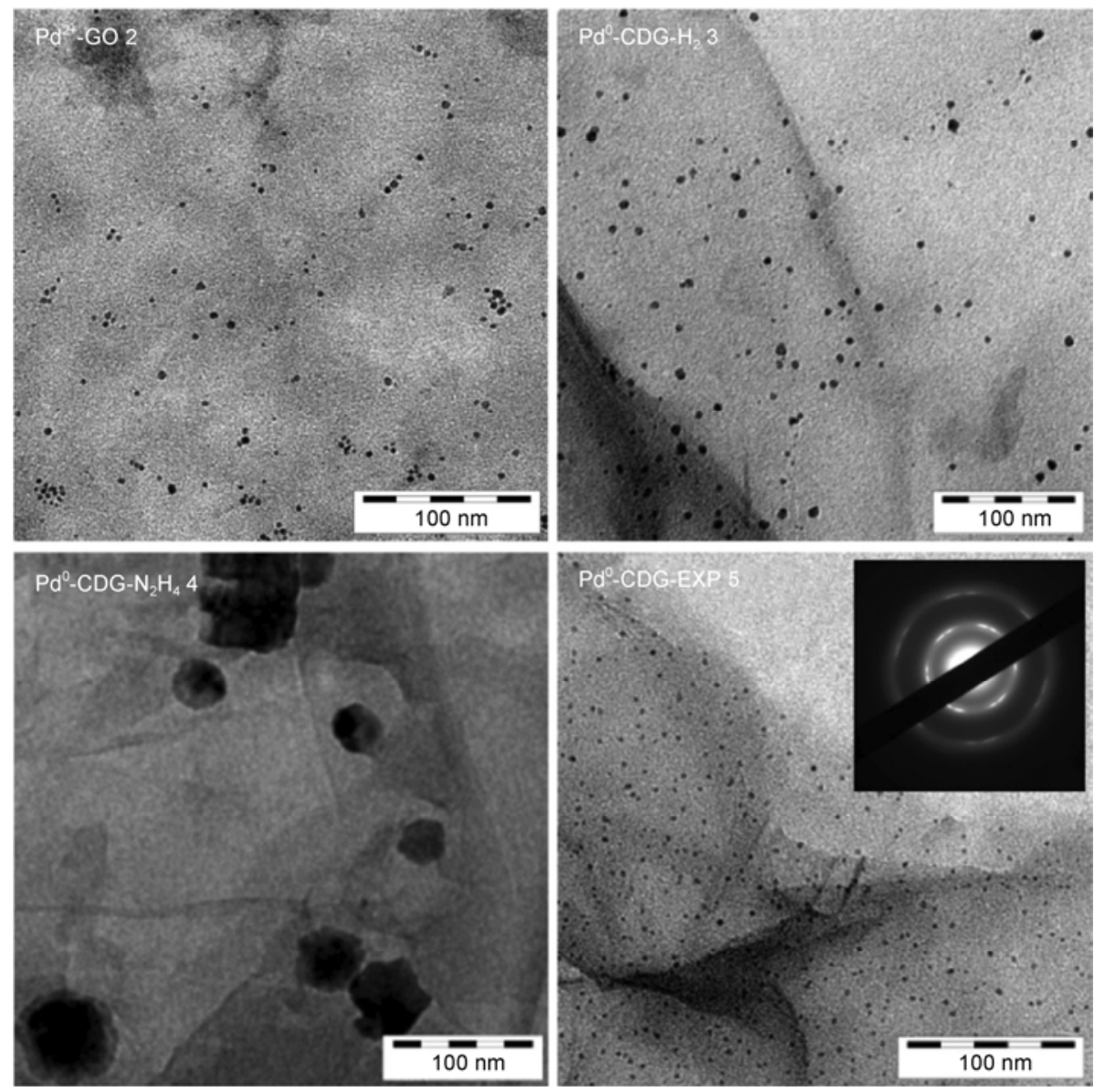

Figure 7 TEM images of the catalysts. Nanoparticles formed simultaneously during the reduction of the graphene oxides. Palladium nanoparticles in $\mathrm{Pd}^{2+}-\mathrm{GO} 2$ were generated in situ during the Suzuki-Miyaura coupling reaction. The SAED in the inset shows a hexagonal pattern that can be ascribed to "regraphitized" regions. Reprinted with permission from [59], Copyright 2009, American Chemical Society. 

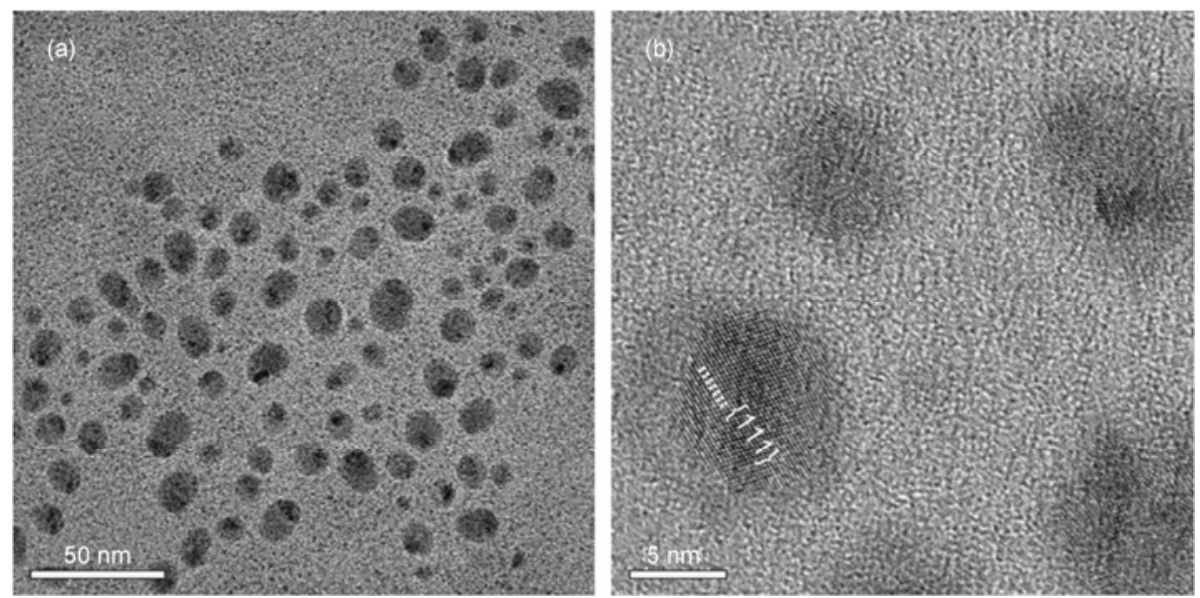

Figure 8 TEM images of RGO-Ag $\left(0.05 \mathrm{mmol} \mathrm{L}^{-1}\right)$ showing well dispersed nanoparticles over a RGO sheet. Reprinted with permission from [66], Copyright 2011, Elsevier.

graphene sheets (FGS) via a facile hydrothermal method and applied the prepared composites to adsorption of methyl orange from aqueous solutions. In the synthesis, exfoliated graphene sheets, $\mathrm{Co}(\mathrm{Ac})_{2}$, and $\mathrm{FeCl}_{3}$ were mixed in aqueous solution with control of the molar ratio and $\mathrm{pH}$ before hydrothermal treatment. The formation mechanism is illustrated in Figure 9. Because of the strong interaction between $\mathrm{Co}^{2+}, \mathrm{Fe}^{3+}$, the graphene surface, and $\mathrm{OH}^{-}$in the suspension, $\mathrm{OH}^{-}$connected the inorganic salt and graphene. The intermediate and final products were adsorbed on the graphene surface, and the $\mathrm{CoFeO}_{4}$ nanoparticles were successfully attached to the surface of graphene nanosheets containing the oxygen functional groups. Compared with magnetic carbon nanotubes, the $\mathrm{CoFe}_{2} \mathrm{O}_{4}$-graphene composites had much higher adsorption capacities $(71 \mathrm{mg} / \mathrm{g}$ at an initial concentration of $10 \mathrm{mg} / \mathrm{L}$ ) with convenient magnetic separation.

Using an alternative method, Fu et al. [68] produced $\mathrm{CoFeO}_{4}$-graphene composites in a one-step solvothermal synthesis in ethanol. The combination of $\mathrm{CoFe}_{2} \mathrm{O}_{4}$ nanoparticles with graphene resulted in a dramatic conversion of the

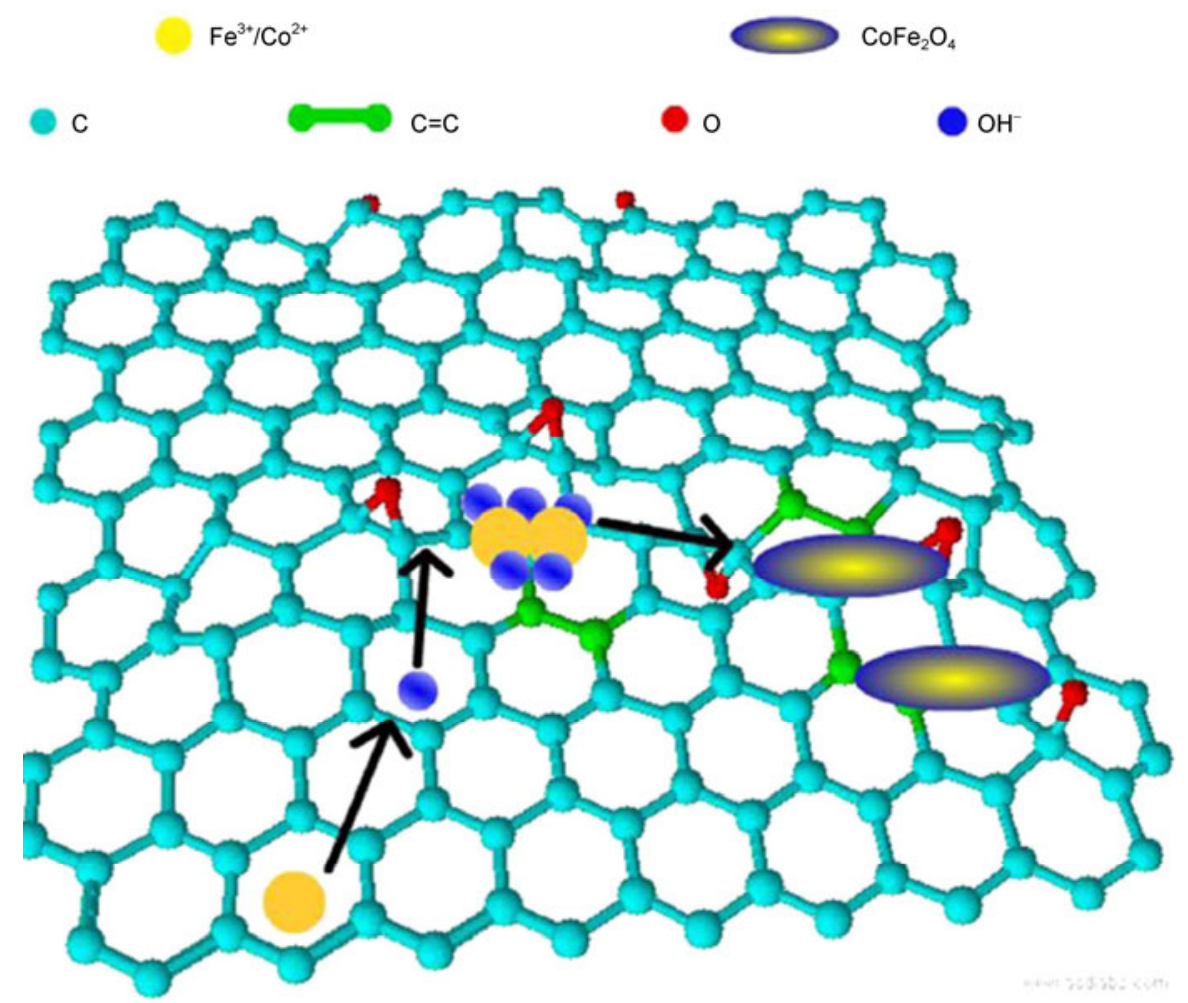

Figure 9 (Color online) Schematic illustration for the formation mechanism of $\mathrm{CoFe}_{2} \mathrm{O}_{4}$-functionalized graphene sheets (FGS). Reprinted with permission from [67], Copyright 2011, Springer Science+Business Media. 


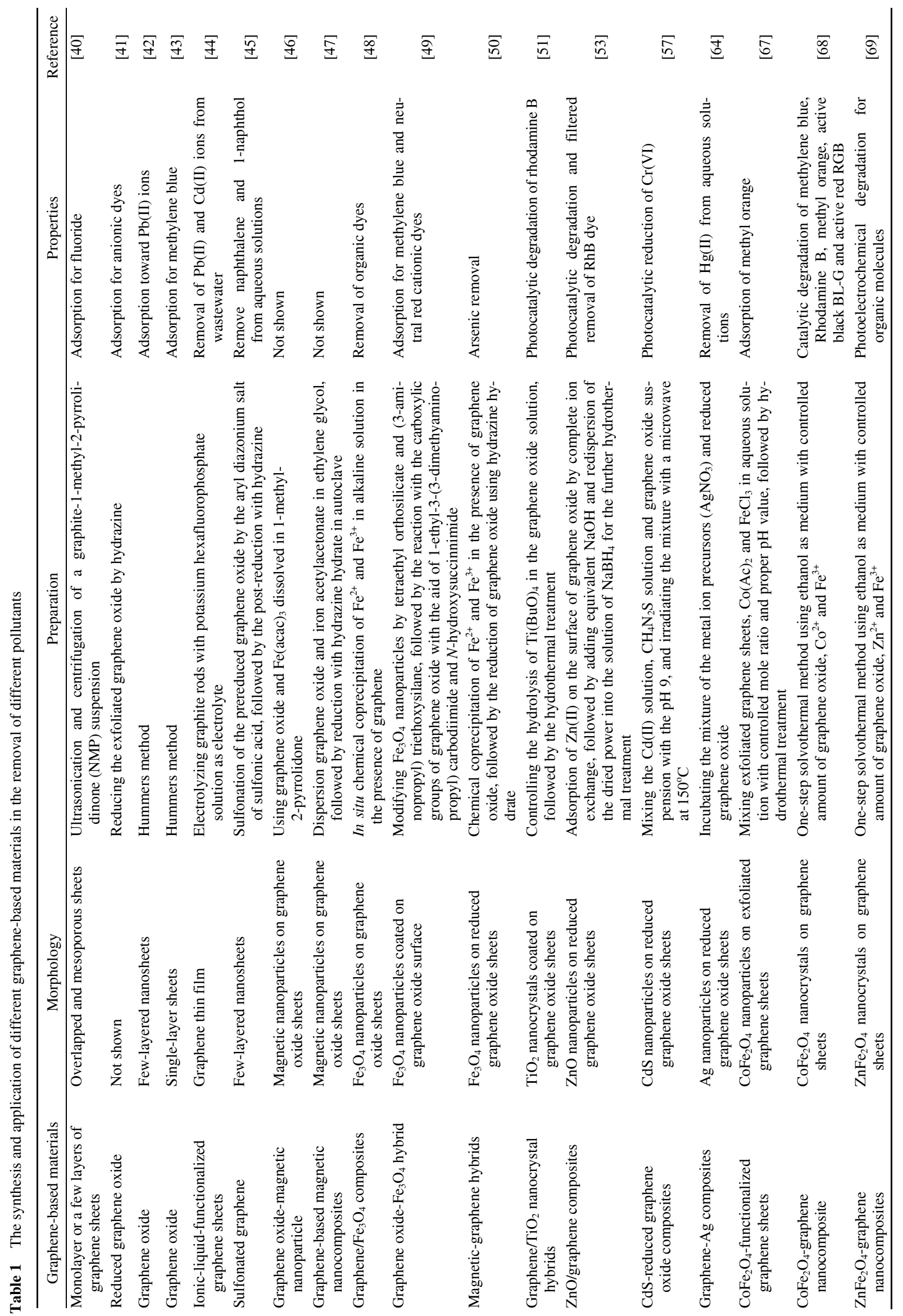


inert $\mathrm{CoFe}_{2} \mathrm{O}_{4}$ into a highly active catalyst for the degradation of methylene blue, Rhodamine $\mathrm{B}$, methyl orange, active black BL-G, and active red RGB without the aid of $\mathrm{H}_{2} \mathrm{O}_{2}$ under visible light irradiation. Because of the inherent magnetism of $\mathrm{CoFe}_{2} \mathrm{O}_{4}$, the suspension could be separated magnetically. Fu et al. [69] also synthesized magnetic $\mathrm{ZnFe}_{2} \mathrm{O}_{4}$ graphene nanocomposites using the same reaction system. Compared with pure $\mathrm{ZnFe}_{2} \mathrm{O}_{4}$, these composites could photoelectrochemically degrade organic molecules and generate hydroxyl radicals $(\cdot \mathrm{OH})$ via photoelectrochemical decomposition of $\mathrm{H}_{2} \mathrm{O}_{2}$ under visible light irradiation. Among nanocomposites with different graphene contents, those containing 20\% (mass fraction) graphene gave the best photocatalytic activity. No noticeable change was observed in the structure or composition after long-term visible light irradiation.

For comparison, the major morphologies, preparation methods, and applications of these graphene-based materials are summarized in Table 1.

\section{The role of graphene-based materials in highly efficient pollutant removal}

Graphene-based materials can be used in a number of ways for environmental remediation and pollutant removal. They can be used to reduce the pollutant concentration by adsorption, decompose pollutants to less toxic molecules (mainly applicable to organic pollutants and persistent organic pollutants), and reduce low-valency species (mainly applicable to toxic high-valency metal ions).

Removal of heavy metal ions from aqueous solution is largely dependent on the interaction between the ions and functional groups on the adsorbents. Therefore, it is understandable that graphene oxide and modified graphenes show high adsorption capacities toward metal ions such as $\mathrm{Cu}$ (II), $\mathrm{Pb}(\mathrm{II}), \mathrm{Cd}(\mathrm{II})$, and $\mathrm{Co}(\mathrm{II})$ [70,71]. According to the literature [70,71], the $\mathrm{pH}$ is important for the adsorption and graphene with a large surface area provides more active sites than one-dimensional carbon nanotubes. Pristine graphene has a lower adsorption capacity than modified graphene in the removal of heavy metal ions.

Graphene-based materials with low aggregation and high specific surface areas show high adsorption capacities for organic pollutants, especially benzene-containing compounds, where the $\pi-\pi$ interaction between graphene and the adsorbate plays a dominant role [72-75]. Therefore, it is important to prevent aggregation between the layers. For convenient separation, magnetic particles are introduced in the adsorbent to form magnetic graphene composites. The added magnetic particles also play an important role in preventing aggregation of the graphene sheets. Therefore, much research has focused on graphene- $\mathrm{Fe}_{3} \mathrm{O}_{4}$ composites for high performance and convenience in pollutant removal and separation of the composites from aqueous solutions. Based on the experimental results and the theory discussed above, pristine graphene has a much higher adsorption capacity than graphene oxide because of the $\pi-\pi$ interaction between the graphene and the organic molecules.

Another approach to remove organic pollutants is photodegradation, in which the degradants can be reused without additional treatment [76]. Graphene-based photodegradants have many advantages over pure photodegradants. First, the unique electronic properties resulting from the $s p^{2}$ hybridized carbon atoms offer a picosecond ultrafast electron transfer process from the excited semiconductors to the graphene sheet. Second, the controllable size of the semiconductors and reduced aggregation of the graphene sheets further improve the efficiency of the photocatalysis. Third, the high transparency of the graphene sheets because of their one- or several-atoms thickness, enhances the utilization of the exciting light. Therefore, the application of graphene-based photodegradants in the decomposition of organic compounds and the reduction of the toxic high-valent metal ions is attractive.

In summary, the unique structure and special properties of graphene make it suitable for modification and complexation with other nanomaterials. The resulting modified graphene and graphene-based composites show high adsorption capacities and photocatalytic abilities.

\section{Conclusion}

Graphene has unique morphology, chemical structure, and electronic properties. It has been synthesized and modified through various methods, and composites have been made with other nanomaterials, such as semiconductors, noble metals, and some complex oxides. These materials have been produced to meet the increasing requirement for highperformance materials for pollutant removal. Graphene-based adsorbents for heavy metal ions and organic pollutants show high adsorption capacities, and graphene-based photocatalysts for use as photoreductants or photodegradants are highly efficient because of their large surface areas, functionalized surfaces, and active photocatalytic nanoparticles. The two-dimensional graphene nanosheet has prompted extensive research in nanomaterials synthesis and has important applications in environmental remediation. Although few graphene-based materials have been produced compared to other well-known nanomaterials, more graphenebased materials will be produced in future with further developments in nanotechnology. Although graphene cannot be synthesized on a large scale and inexpensively, there is no doubt that graphene or graphene-based materials will be easily and inexpensively produced in large quantities in the near future. The outstanding physicochemical properties of graphene and graphene-based materials will play a very important role in environmental pollution management in the future. 
This work was supported by the National Basic Research Program of Chi$n a(2011 C B 933700$ and 2007CB936602) and the National Natural Science Foundation of China (20971126, 21071147, 21071107 and 91126020).

1 Lee C, Wei X, Kysar J W, et al. Measurement of the elastic properties and intrinsic strength of monolayer graphene. Science, 2008, 321: 385-388

2 Balandin A A, Ghosh S, Bao W, et al. Superior thermal conductivity of single-layer graphene. Nano Lett, 2008, 8: 902-907

3 Park S, Ruoff R S. Chemical methods for the production of graphenes. Nat Nanotechnol, 2009, 4: 217-224

4 Rao C N R, Sood A K, Subrahmanyam K S, et al. Graphene: The new two-dimensional nanomaterial. Angew Chem Int Ed, 2009, 48: 7752-7777

5 Ma Y W, Zhang L R, Li J J, et al. Carbon-nitrogen/graphene composite as metal-free electrocatalyst for the oxygen reduction reaction. Chin Sci Bull, 2011, 56: 3583-3589

6 Tian L L, Zhuang Q C, Li J, et al. Mechanism of intercalation and deintercalation of lithium ions in graphene nanosheets. Chin Sci Bull, 2011, 56: 3204-3212

7 Wang H W, Wu H Y, Chang Y Q, et al. Tert-butylhydroquinonedocorated graphene nanosheets and their enhanced capacitive behaviors. Chin Sci Bull, 2011, 56: 2092-2097

8 Zhang Q O, He Y Q, Chen X G, et al. Structure and photocatalytic properties of $\mathrm{ThO}_{2}$-graphene oxide intercalated composite. Chin Sci Bull, 2011, 56: 331-339

9 Zhang H, Fu Q, Cui Y, et al. Fabrication of metal nanoclusters on graphene grown on $\mathrm{Ru}(0001)$. Chin Sci Bull, 2009, 54: 2446-2450

10 Zhang M Y, Wang Y, Zhao D Y, et al. Immobilization of arsenic in soils by stabilized nanoscale zero-valent iron, iron sulfide (FeS), and magnetite $\left(\mathrm{Fe}_{3} \mathrm{O}_{4}\right)$ particles. Chin Sci Bull, 2010, 55: 365-372

11 Meyer J C, Geim A, Katsnelson M, et al. The structure of suspended graphene sheets. Nature, 2007, 446: 60-63

12 Ferrari A, Meyer J, Scardaci V, et al. Raman spectrum of graphene and graphene layers. Phys Rev Lett, 2006, 97: 187401

13 Li X, Cai W, An J, et al. Large-area synthesis of high-quality and uniform graphene films on copper foils. Science, 2009, 324: 13121314

14 Reina A, Jia X, Ho J, et al. Large area, few-layer graphene films on arbitrary substrates by chemical vapor deposition. Nano Lett, 2008, 9: 30-35

15 Srivastava A, Galande C, Ci L, et al. Novel liquid precursor-based facile synthesis of large-area continuous, single, and few-layer graphene films. Chem Mater, 2010, 22: 3457-3461

16 Sutter P W, Flege J I, Sutter E A. Epitaxial graphene on ruthenium. Nat Mater, 2008, 7: 406-411

17 Vang R T, Honkala K, Dahl S, et al. Controlling the catalytic bond-breaking selectivity of $\mathrm{Ni}$ surfaces by step blocking. Nat Mater, 2005, 4: 160-162

18 Nandamuri G, Roumimov S, Solanki R. Chemical vapor deposition of graphene films. Nanotechnology, 2010, 21: 145604

19 Aristov V Y, Urbanik G, Kummer K, et al. Graphene synthesis on cubic SiC/Si wafers. Perspectives for mass production of graphenebased electronic devices. Nano Lett, 2010, 10: 992-995

20 Deng D, Pan X, Zhang H, et al. Freestanding graphene by thermal splitting of silicon carbide granules. Adv Mater, 2010, 22: 2168-2171

21 Emtsev K V, Bostwick A, Horn K, et al. Towards wafer-size graphene layers by atmospheric pressure graphitization of silicon carbide. Nat Mater, 2009, 8: 203-207

22 Shivaraman S, Barton R A, Yu X, et al. Free-standing epitaxial graphene. Nano Lett, 2009, 9: 3100-3105

23 Subrahmanyam K, Panchakarla L, Govindaraj A, et al. Simple method of preparing graphene flakes by an arc-discharge method. J Phys Chem C, 2009, 113: 4257-4259

24 Wu Z S, Ren W, Gao L, et al. Synthesis of graphene sheets with high electrical conductivity and good thermal stability by hydrogen arc discharge exfoliation. Acs Nano, 2009, 3: 411-417

25 Hirsch A. Unzipping carbon nanotubes: A peeling method for the formation of graphene nanoribbons. Ang Chem Int Ed, 2009, 48: 6594-6596

26 Jiao L, Zhang L, Wang X, et al. Narrow graphene nanoribbons from carbon nanotubes. Nature, 2009, 458: 877-880

27 Kosynkin D V, Higginbotham A L, Sinitskii A, et al. Longitudinal unzipping of carbon nanotubes to form graphene nanoribbons. Nature, 2009, 458: 872-876

28 Guo H L, Wang X F, Qian Q Y, et al. A green approach to the synthesis of graphene nanosheets. Acs Nano, 2009, 3: 2653-2659

29 Shao Y, Wang J, Engelhard M, et al. Facile and controllable electrochemical reduction of graphene oxide and its applications. J Mater Chem, 2009, 20: 743-748

30 Zhou M, Wang Y, Zhai Y, et al. Controlled synthesis of large-area and patterned electrochemically reduced graphene oxide films. Chem Eur J, 2009, 15: 6116-6120

31 Simpson C D, Brand J D, Berresheim A J, et al. Synthesis of a giant 222 carbon graphite sheet. Chem Eur J, 2002, 8: 1424-1429

32 Berresheim A J, Müller M, Müllen K. Polyphenylene nanostructures. Chem Rev, 1999, 99: 1747-1786

33 Sakamoto J, van Heijst J, Lukin O, et al. Two-dimensional polymers: Just a dream of synthetic chemists? Angew Chem Int Ed, 2009, 48: 1030-1069

$34 \mathrm{Wu} \mathrm{J}$, Gherghel L, Watson M D, et al. From branched polyphenylenes to graphite ribbons. Macromolecules, 2003, 36: 7082-7089

35 Wu J, Pisula W, Müllen K. Graphenes as potential material for electronics. Chem Rev, 2007, 107: 718-747

36 Yan X, Cui X, Li B, et al. Large, solution-processable graphene quantum dots as light absorbers for photovoltaics. Nano Lett, 2010, 10: $1869-1873$

37 Yang X, Dou X, Rouhanipour A, et al. Two-dimensional graphene nanoribbons. J Am Chem Soc, 2008, 130: 4216-4217

38 Compton O C, Nguyen S B T. Graphene oxide, highly reduced graphene oxide, and graphene: Versatile building blocks for carbonbased materials. Small, 2010, 6: 711-723

39 Rao C, Sood A, Subrahmanyam K, et al. Graphene: The new twodimensional nanomaterial. Angew Chem Int Ed, 2009, 48: 7752-7777

40 Li Y, Zhang P, Du Q, et al. Adsorption of fluoride from aqueous solution by graphene. J Colloid Interface Sci, 2011, 363: 348-354

41 Ramesha G, Vijaya K A, Muralidhara H, et al. Graphene and graphene oxide as effective adsorbents toward anionic and cationic dyes. J Colloid Interface Sci, 2011, 361: 270-277

42 Zhao G, Ren X, Gao X, et al. Removal of $\mathrm{Pb}$ (II) ions from aqueous solutions on few-layered graphene oxide nanosheets. Dalton Trans, 2011, 40: 10945-10952

43 Yang S T, Chen S, Chang Y, et al. Removal of methylene blue from aqueous solution by graphene oxide. J Colloid Interface Sci, 2011, 359: 24-29

44 Deng $\mathrm{X}$, Lü L, Li H, et al. The adsorption properties of $\mathrm{Pb}$ (II) and $\mathrm{Cd}(\mathrm{II})$ on functionalized graphene prepared by electrolysis method. J Hazard Mater, 2010, 183: 923-930

45 Zhao G, Jiang L, He Y, et al. Sulfonated graphene for persistent aromatic pollutant management. Adv Mater, 2011, 23: 3959-3963

46 Shen J, Hu Y, Shi M, et al. One step synthesis of graphene oxidemagnetic nanoparticle composite. J Phys Chem C, 2010, 114: 14981503

47 Shen X, Wu J, Bai S, et al. One-pot solvothermal syntheses and magnetic properties of graphene-based magnetic nanocomposites. J Alloy Comp, 2010, 506: 136-140

48 Wang C, Feng C, Gao Y, et al. Preparation of a graphene-based magnetic nanocomposite for the removal of an organic dye from aqueous solution. Chem Eng J, 2011, 173: 92-97

$49 \mathrm{He} \mathrm{F}$, Fan J, Ma D, et al. The attachment of $\mathrm{Fe}_{3} \mathrm{O}_{4}$ nanoparticles to graphene oxide by covalent bonding. Carbon, 2010, 48: 3139-3144

50 Chandra V, Park J, Chun Y, et al. Water-dispersible magnetite-reduced graphene oxide composites for arsenic removal. ACS Nano, 2010, 4: 3979-3986

51 Liang $\mathrm{Y}$, Wang $\mathrm{H}$, Sanchez $\mathrm{C} \mathrm{H}$, et al. $\mathrm{TiO}_{2}$ nanocrystals grown on graphene as advanced photocatalytic hybrid materials. Nano Res, 2010, 3: 701-705 
52 Zhang H, Lv X, Li Y, et al. P25-graphene composite as a high performance photocatalyst. ACS Nano, 2009, 4: 380-386

53 Zhang L, Xu T, Cheng H, et al. Significantly enhanced photocatalytic performance of $\mathrm{ZnO}$ via graphene hybridization and the mechanism study. Appl Catal B: Environ, 2011, 101: 382-387

54 Nethravathi C, Nisha T, Ravishankar N, et al. Graphene-nanocrystalline metal sulphide composites produced by a one-pot reaction starting from graphite oxide. Carbon, 2009, 47: 2054-2059

55 Wang K, Liu Q, Wu X Y, et al. Graphene enhanced electrochemiluminescence of CdS nanocrystal for $\mathrm{H}_{2} \mathrm{O}_{2}$ sensing. Talanta, 2010, 82: 372-376

56 Chang H, Lü X, Zhang H, et al. Quantum dots sensitized graphene: In situ growth and application in photoelectrochemical cells. Electrochem Commun, 2010, 12: 483-487

57 Liu X, Pan L, Lü T, et al. Microwave-assisted synthesis of CdS Creduced graphene oxide composites for photocatalytic reduction of Cr(VI). Chem Commun, 2011, 47: 11984-11986

58 Muszynski R, Seger B, Kamat P V. Decorating graphene sheets with gold nanoparticles. J Phys Chem C, 2008, 112: 5263-5266

59 Scheuermann G M, Rumi L, Steurer P, et al. Palladium nanoparticles on graphite oxide and its functionalized graphene derivatives as highly active catalysts for the Suzuki-Miyaura coupling reaction. J Am Chem Soc, 2009, 131: 8262-8270

60 Goncalves G, Marques P A A P, Granadeiro C M, et al. Surface modification of graphene nanosheets with gold nanoparticles: The role of oxygen moieties at graphene surface on gold nucleation and growth. Chem Mater, 2009, 21: 4796-4802

61 Zhang H, Chen S, Quan X, et al. In situ controllable growth of noble metal nanodot on graphene sheet. J Mater Chem, 2011, 21: 1298612990

62 Kamat P V. Graphene-based nanoarchitectures. Anchoring semiconductor and metal nanoparticles on a two-dimensional carbon support. J Phys Chem Lett, 2009, 1: 520-527

63 Guo S, Dong S, Wang E. Three-dimensional Pt-on-Pd bimetallic nanodendrites supported on graphene nanosheet: Facile synthesis and used as an advanced nanoelectrocatalyst for methanol oxidation. ACS Nano, 2009, 4: 547-555

64 Liu J, Fu S, Yuan B, et al. Toward a universal adhesive nanosheet for the assembly of multiple nanoparticles based on a protein-induced reduction/decoration of graphene oxide. J Am Chem Soc, 2010, 132:
7279-7281

65 Zhao H, Yang J, Wang L, et al. Fabrication of a palladium nanoparticle/ graphene nanosheet hybrid via sacrifice of a copper template and its application in catalytic oxidation of formic acid. Chem Commun, 2011, 47: 2014-2016

66 Sreeprasad T, Maliyekkal S M, Lisha K, et al. Reduced graphene oxidemetal/metal oxide composites: Facile synthesis and application in water purification. J Hazard Mater, 2011, 186: 921-931

$67 \mathrm{Li} \mathrm{N}$, Zheng M, Chang X, et al. Preparation of magnetic $\mathrm{CoFe}_{2} \mathrm{O}_{4}$ functionalized graphene sheets via a facile hydrothermal method and their adsorption properties. J Solid State Chem, 2011, 184: 953-958

68 Fu Y, Chen H, Sun X, et al. Combination of cobalt ferrite and graphene: High-performance and recyclable visible-light photocatalysis. Appl Catal B: Environ, 2011, doi:10.1016/j.apcatb.2011.10.009

$69 \mathrm{Fu} \mathrm{Y}$, Wang X. Magnetically separable $\mathrm{ZnFe}_{2} \mathrm{O}_{4}$-graphene catalyst and its high photocatalytic performance under visible light irradiation. Ind Eng Chem Res, 2011, 50: 7210-7218

70 Li Y H, Ding J, Luan Z, et al. Competitive adsorption of $\mathrm{Pb}^{2+}, \mathrm{Cu}^{2+}$ and $\mathrm{Cd}^{2+}$ ions from aqueous solutions by multiwalled carbon nanotubes. Carbon, 2003, 41: 2787-2792

71 Zhao G X, Li J X, Ren X M, et al. Few-layered graphene oxide nanosheets as superior sorbents for heavy metal ion pollution management. Environ Sci Technol, 2011, 45: 10454-10462

72 Zhao G X, Li J X, Wang X K. Kinetic and thermodynamic study of 1-naphthol adsorption from aqueous solution to sulfonated graphene nanosheets. Chem Eng J, 2011, 173: 185-190

73 Yang S B, Hu J, Chen C L, et al. Mutual effect of $\mathrm{Pb}$ (II) and humic acid adsorption onto multiwalled carbon nanotubes/poly(acrylamide) composites from aqueous solution. Environ Sci Technol, 2011, 45: 3621-3627

74 Shao D D, Hu J, Jiang Z Q, et al. Removal of 4,4'-dichlorinated biphenyl from aqueous solution using methyl methacrylate grafted multiwalled carbon nanotubes. Chemosphere, 2011, 82: 751-758

75 Shao D D, Sheng G D, Chen C L, et al. Removal of polychlorinated biphenyls from aqueous solutions using $\beta$-cyclodextrin grafted multiwalled carbon nanotubes. Chemosphere, 2010, 79: 679-685

76 Zhao D L, Chen C L, Sheng G D, et al. Enhanced photocatalytic degradation of methylene blue under visible irradiation on graphene@ $\mathrm{TiO}_{2}$ Drade structure. Appl Catal B: Environ, 2012, 111-112: 303-308

Open Access This article is distributed under the terms of the Creative Commons Attribution License which permits any use, distribution, and reproduction in any medium, provided the original author(s) and source are credited. 